九州大学学術情報リポジトリ

Kyushu University Institutional Repository

\title{
Pitch Problems in Making Japanese Papers (IV) Occurrence of Deposits in Pulping and Bleaching of Pokasa Bast Fibers
}

Su, Yu-Chang

Laboratory of Industrial Chemistry of Wood, Faculty of Agriculture, Kyushu University

Tachibana, Sanro

Laboratory of Industrial Chemistry of Wood, Faculty of Agriculture, Kyushu University

Sumimoto, Masashi

Laboratory of Industrial Chemistry of Wood, Faculty of Agriculture, Kyushu University I

Laboratory of Industrial Chemistry of Wood, Faculty of Agriculture, Kyushu University

https://doi.org/10.5109/24001

出版情報：九州大学大学院農学研究院紀要. 37 (1)，pp. 105-116，1992-12. Kyushu University バージョン：

権利関係: 


\title{
Pitch Problems in Making J apanese Papers (IV) $O$ ccurrence of Deposits in Pulping and Bleaching of Pokasa Bast Fibers
}

\author{
Yu-Chang Su*, Sanro Tachibana** and M asashi Sumimoto \\ Laboratory of Industrial Chemistry of Wood, Faculty Agriculture, \\ Kyushu University 46-08, Fukuoka 812, Japan
}

(Received June 17, 1992)

\begin{abstract}
Deposition of organic and inorganic substances in pokasa (Broussonetia papurifera) bark pulping and bleaching sequences was studied from the view point of material balance between the/organic and the inorganics fractions. Little differences among the fractions were found, but better recovery yields of Fr.II chip neutrals indicated lower solubilities of these substances in aqueous phase or higher depositabilities on pulp. Fr.II contained triterpene acetates which were shown to interact easily with either acids or calcium as descibed in a previous paper. The higher depositability again confirmed its contribution to speck formation. Moreover, mass balance of the inorganics suggested that calium carbonate was formed during pulping and readsorbed onto the fibers. Calcium cation $\left(\mathrm{Ca}^{++}\right)$, calcium carbonate $\left(\mathrm{CaCO}_{3}\right)$ or calcium oxalate $\left(\mathrm{CaC}_{2} \mathrm{O}_{4}\right)$ have almost the same degree of contribution to the speck formation. A hypothetical mechanism for the interactions among fibers, calcium, any organic acids was presented as follows:

1. Acidic components react with $\mathrm{Ca}++$ or $\mathrm{CaCO}_{3}$ to form salts or complexes with positive charges, which were adsorbed onto pulp with negative charges on its surface.

2. In pulping, $\mathrm{Ca}++$ ions are generates and adsorbed on the vicinities of the resinous materials to form colloids with positive charges and adsorb onto pulp which have negative charges.

3. Calcium carbonate in aqueous medium may be coordinated by six molecules of $\mathrm{H}_{2} \mathrm{O}$ to form $\mathrm{Ca}\left(\mathrm{H}_{2} \mathrm{O}\right)_{6}{ }^{++}$due to the coordinating properties of the ligand $\mathrm{OH}$ anion being substituted by $\mathrm{H}_{2} \mathrm{O}$ molecule. Resinous materials may be directly bonded to the ions and may also bond with hydroxyl groups in cellulosic fibers.
\end{abstract}

\section{INTRODUCTION}

In previous papers (Su et al., 1984, 1986, 1992), the formation of ink-repellent specks was considered to be the results of interaction between the resinous materials and inorganics. The resinous materials were found to be composed of alkanes and acids, fatty acids, and phenolic acids. Among the inorganics which are responsible for speck formation, calcium was the major and magnesium the minor factors.

In this paper, changes in the amounts and rations of the organic fractions, and Changes of inorganics balance caused by pulping and bleaching were discussed.

\footnotetext{
* Present address: Taiwan Forestry Research Institute

** Present address: Faculty of Agriculture, Ehime University
} 
Deposited pitch on the cooking equipment was also analyzed. The forms of calcium and magnesium in bark chips, unbleached (UP) and bleached pulps (BP) as well as their influences on speck formation are also discussed.

\section{MATERIALS AND METHODS}

\section{Extraction and Fractionation}

One hundred grams of samples (bark, unbleached pulp, bleached pulp) were extracted thrice with $\mathrm{MeOH}$ at boiling temperature for $8 \mathrm{~h}$. After evaporation of the solvent the extractives were fractioned into neutrals, phenols, and acids, by the usual manner and further separation were also conducted as discussed in the previous paper (Su et al., 1984, 1986).

\section{Fractionation of the Deposited Substances to the Cooking Equipment}

The deposit was vaccumed-dried at $40^{\circ} \mathrm{C}$ for two days. The dried sample $(10 \mathrm{~g})$ was weighed and extracted with Soxhlet apparatus for $12 \mathrm{~h}$ with acetone $(200 \mathrm{~mL})$. The residue was then extracted with chloroform. Both acetone and chloroform extracts were evaporated separately to dryness in vacuo and weighed. Acetone extractives were further fractionated into neutrals, phenols, and acids. Chloroform extracts were hydrolyzed with dilute $\mathrm{HCl}$ solution for $2 \mathrm{~h}$ and extracted with ethyl acetate. Water layer was then titrated with EDTA to determine the calcium and magnesium contents. After the extractives-free residues were burned off in a electrical furnace, calcium, magnesium, silica contents were determined in the usual manner ( $\mathrm{Su}$ et al., 1984).

\section{Determination of $M$ etallic Carbonate in Bark, UP,BP, and Deposited Substances}

Bark,UP,BP,and deposited substances were milled with a Willy mill to pass $20-40$ mesh separately. Ten grams of each sample was weighed in a three necked flask. One hundred $\mathrm{mL}$ of $20 \% \mathrm{HCl}$ were added dropwise under a nitrogen atomsphere. The carbon dioxide gas generated were trapped by soda talc blue (Wako reagent 6-10 mesh) and the amounts of carbon dioxide were quantitively determined. Amendment was carried out by a blank test. Calibration curve showing the relation between the generated carbon dioxide with concentration of the carbonate was prepared by using known amounts of pure sodium carbonate. The calculated values of metallic carbonate $/(\mathrm{CaO}+\mathrm{MgO})$ were thus obtained.

\section{Contribution of Various Types of Calcium to Speck Formation}

Eighty $\mathrm{mg}$ of methanol extractive of pokasa bark were re-added to $2 \mathrm{~g}$ of acidwashed, extratives-free pokasa pulp as described in a previous paper ( $\mathrm{Su}$ et al., 1984). Each $100 \mathrm{mg}$ (as $\mathrm{CaO}$ ) of various Calcium forms, namely $\mathrm{CaCl}_{2}, \mathrm{CaCO}_{3}$ and $\mathrm{CaC}_{2} \mathrm{O}_{4}$, was then added separately to extractives-readded pulp. The re-addition test was conducted as in a previous paper, the speck area was then determined. A part of these pulps was incinerated separately and determination of calcium was made as mentioned in a previons paper (Su et al., 1986). 


\section{RESULTS AND DISCUSSIONS}

Changes in the Amounts of the Resinous Fractions by Pulping and Bleaching

Changes in amounts and rations of the resinous fractions caused by pulping and bleaching are shown in Table 1. For comparison, the amounts and rations of the resinous fractions deposited on the cooking equipment are also listed in the table. As a result of alkaline cooking, about $60 \%$ of the bark chips resin was shown to be dissolved out. The solubilized part included the newly formed acids through saponification of the original ester fraction, in addition to the original acidic and phenolic fractions. These fractions functioned as surfactants to solubilize the neutrals in the aqueous alkaline liquor (Abe,1987). However, most of the ethyl acetate solubles of UP resins were neutrals, which were the major factors for speck formation as mentioned in previos papers (Su et al., 1984, 1986, 1992). At the bleaching stage, a slight increase of the amounts of residual resin was found, i.e., as $\mathrm{MeOH}$ extractives or EtOAc solubles from bleached pulps were greater in amounts compared to the unbleached pulps. The reason for the relative large decrease in neutral fraction and the slight increase in phenolic fraction remained obscure.

Qualitative analyses of each resinous fraction from bark, UP, and BP were made by thin layer chromatography and the results shown in Figure 1. No apparent chemical conversion of the neutral, acidic, and phenolic fractions during pulping and bleaching was found. Major components of the neutrals from bark, UP, and BP extractives were

Table 1. Changes in the amounts of resin contents at the different stage.

\begin{tabular}{lllll}
\hline Components & Bark Resin & UP Resin & BP Resin & Deposited resin \\
\cline { 2 - 5 } MeOH Extrs. & $4.41^{\prime \prime \prime}(100)^{\mathrm{d})}$ & $2.94^{\mathrm{b})}(38.8)^{\mathrm{d})}$ & $3.23^{\mathrm{c})}(39.9)^{\mathrm{d})}$ & $0.47^{\prime \prime \prime}$ \\
EtOAc Insois. & $1.39^{\mathrm{a})}(31.5)^{\mathrm{d})}$ & $0.38^{\mathrm{b})}(5.0)^{\mathrm{d})}$ & $0.46^{\mathrm{c})}(5.7)^{\mathrm{d})}$ & $0.04^{\mathrm{e})}$ \\
EtOAc Sois. & $3.02^{\mathrm{a})}(68.5)^{\mathrm{d})}$ & $2.56^{\mathrm{b})}(33.8)^{\mathrm{d})}$ & $2.77^{\mathrm{c})}(34.2)^{\mathrm{d})}$ & $0.43^{\prime \prime \prime}$ \\
Neutrais & $2.37^{\mathrm{a})}(53.7)^{\mathrm{d})}$ & $2.31^{\mathrm{b}}(20.5)^{\mathrm{d})}$ & $2.06^{\mathrm{c}}(25.4)^{\mathrm{d})}$ & $0.35^{\prime \prime}$ \\
Phenois & $0.50^{\mathrm{a})}(11.3)^{\mathrm{d})}$ & $0.16^{\mathrm{b})}(2.2)^{\mathrm{d})}$ & $0.64^{\mathrm{c})}(7.9)^{\mathrm{d})}$ & $0.05^{\mathrm{e})}$ \\
Acids & $0.15^{\mathrm{a})}(3.4)^{\mathrm{d})}$ & $0.08^{\mathrm{b})}(1.1)^{\mathrm{d})}$ & $0.07^{\mathrm{c})}(0.9)^{\mathrm{d})}$ & $0.03^{\prime \prime}$ \\
\hline
\end{tabular}

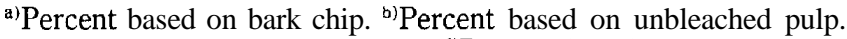

c) Percent based on bleached pulp. d)Percent based on the amounts of total bark resin.

e)Percent based on the deposited substances.

Table 2. Relative amounts of the mojor neutral components at the different stages.

\begin{tabular}{lcccc}
\hline Compenents & Bark Neutrals* & UP Neutrals* & BP Neutrals* & $\begin{array}{c}\text { Deposited } \\
\text { Neutrals }\end{array}$ \\
\hline Total & & & & \\
Neutrals & $2.37^{\mathrm{a})}(100)^{\mathrm{d})}$ & $2.31^{\mathrm{b})}(56.5)^{\mathrm{d})}$ & $2.06^{\mathrm{c})}(47.3)^{\mathrm{d})}$ & $0.35^{\prime \prime}$ \\
Fr. II & $0.87^{\mathrm{a}}(36.7)^{\mathrm{d})}$ & $1.10^{\mathrm{b}}(26.9)^{\mathrm{d})}$ & $0.98^{\mathrm{c}}(22.5)^{\mathrm{d})}$ & $0.23^{\prime \prime}$ \\
Fr. III & $0.42^{\mathrm{a})}(17.7)^{\mathrm{d})}$ & $0.31^{\mathrm{b})}(7.6)^{\mathrm{d})}$ & $0.20^{\mathrm{c}}(4.6)^{\mathrm{d})}$ & $0.05^{\prime \prime}$ \\
Fr. IV & $0.37^{\mathrm{a}}(15.6)^{\mathrm{d})}$ & $0.28^{\mathrm{b}}(6.9)^{\mathrm{d})}$ & $0.20^{\mathrm{c})}(4.6)^{\mathrm{d})}$ & $0.03^{\prime \prime}$ \\
\hline
\end{tabular}

*Actural values determined either by direct separation or by chromatoscanner.

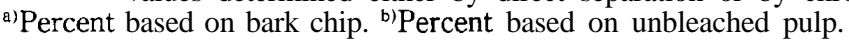

${ }^{\text {c) }}$ Percent based on bleached pulp. ${ }^{\text {d) }}$ Percent based on the amounts of total bark resin.

e)Percent based on the deposited substances. 
quantitatively determined by the use of chromatoscanner equipped with ion flame detector. The results are shown in Table 2. Better recovery yields of Fr.II in pulps compared to those of Frs.III and IV were resulted from its lower solubility in aqueous phase or higher depositability onto the pulp.

Though the details of the deposited resins, which were collected in a paper mill, will be discussed in a following section, the deposited neutrals also show the better yields of Fr.II as compared with those of Frs.III and IV. Deposited resins of this kind may be resins once dissolved out of the chips and then deposited after cooling. In this case, depositability may be a greater cause then solubility and resulting in the higher ratio of Fr.II in deposited resin. The results supported the findings described in a previous paper that Fr.II of the neutrals showed the largest contribution in both the speck formation and the $\Delta \tau$ values. About $70 \%$ of the deposited neutrals consisted of Fr.II. Details about this fraction is discussed in a later section. As noted before $\mathrm{Su}$ et al., 1986), Fr.II and Fr.IV of the neutrals are made up of the complex mixture of triterpene esters and the corresponding alcohols. This type of macrocyclic compounds are noted for their depositable character and are also considered to be responsible for pitch problems in kraft pulping of tropical wood, such as dipterocarpol in apiton (Kayama, 1967, 1969), hydroxydammarenone and ocotillone in Diterocarpus spp. (Shimada, 1969) The high aggregation trends of triterpenoid Fr.II and IV closely related to their depositability and was well proven in a previous paper ( $\mathrm{Su}$, et al., 1986).

\section{Separation and Analyses of Deposited Substances}

Deposited materials were collected in Chan-Chun Paper Manufacturing Co. (Taiwan), where pokasa were used as raw materials in making washi (a kind of handmade bast paper). The deposited materials can be fractionated by the procedure described in Figure 2, and the results are shown in Table 3. Surprisingly, the acetone extracts,

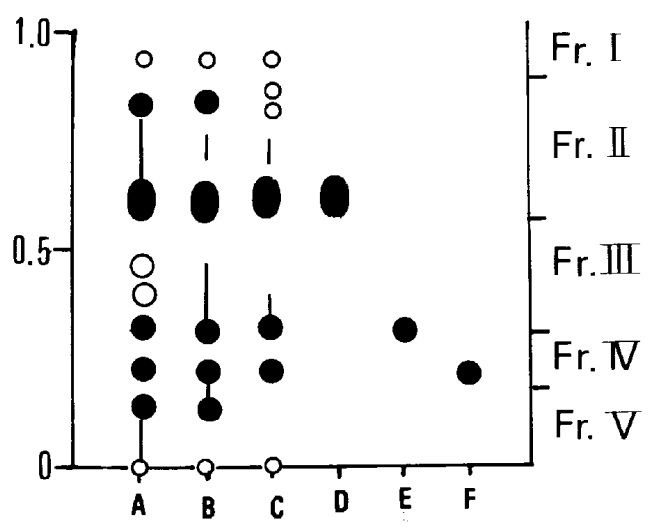

Fig. 1. TLC chromatograms of the neutrals. A : Chip neutrals B : UP and BP neutrals, C : Deposit neutrals, D : fr. II-5 of A. E : fr, III-2 of A, F : fr. IV of A. Developing solvent : benzene :IItOAc: $\mathrm{IICO}_{2} \mathrm{II}=50: 4: 1$. 


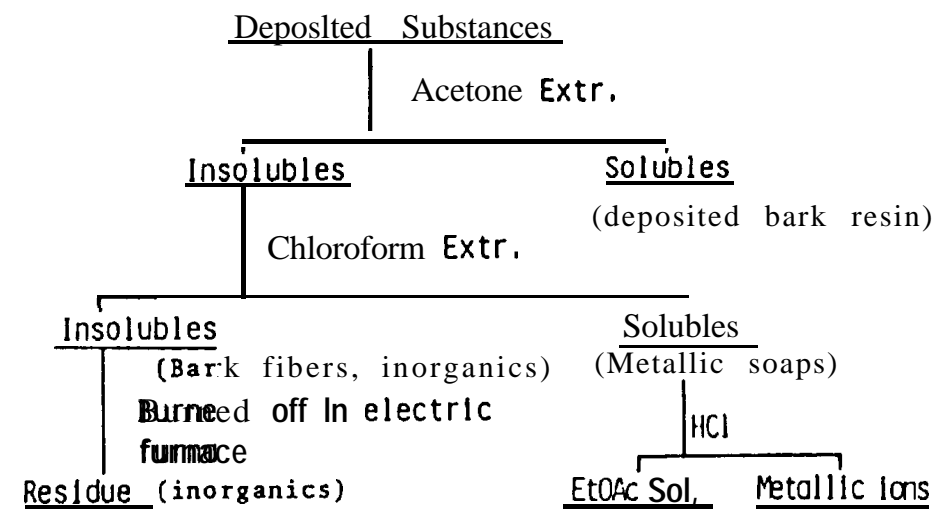

Fig. 2. Fractionation scheme of deposited Substances.

determinants of bark resins were only $4.16 \%$, while the chloroform extracts probably comprised of metallic soaps of fatty acids, triterpene acids and phenolic acids were merely $0.43 \%$. Cellulosic fibers made up about $30 \%$, and inorganics about $70 \%$ of the deposited materials. This is quite different from the pitch deposition of kraft pulping, where wood resin and calcuim soaps have been found to be the major components (Deouk and Allen, 1980).

\section{Analyses of the Acetone Extracts from Deposited Substances}

The acetone extracts were separated into acidic phenolic and neutral fractions by the usual manner to give the rations as shown in Table 3 . The rations of the phenolics and the acids are extremely low as compared with the neutrals. Thin layer chromatograms are quite similar for the corresponding fractions at three processing stages, namely barks, UP, and BP, as decribed in the previous section. Further analysis was omitted. The neutral components also appear similar to those obtained from bark and UP. As a major fraction, separation was made according to the manner described in a previous paper to give the corresponding Frs.I-VI. As shown in Figure 1. Except for some differences in yields, the bark and deposited neutrals are quite smiliar to each other. Their UV and IR spectra and the Liebermann-Burchard test also indicated their similiarity to each other. And both contained a complex mixture of triterpene esters. Further identification was made by HPLC to compare the retention time with the Fr. II-5 from the bark neutrals. Comparison of Fr.II-5 of bark neutrals with those of corresponding fr.II of deposited neutrals were made as shown in Figure 3. The retention time were identitical with authentic samples of lupenyl formate, $\delta$-amyrin acetate, $\alpha$-amyrin acetate, $\beta$-amyrin acetate, bauerenyl acetate and laupenyl acetate, all of which had been isolated from the bark extractives. Large amounts of these compounds remained in deposited pitch confirmed their depositable characters.

\section{M etallic Soaps from the Deposited Substance}

The chloroform extracts comprising metallic soaps were hydrolyzed with dilute $\mathrm{HCl}$ and sequentially extracted with ethyl acetate. Metallic ions released into aqueous 
the water layer were trapped by the method of chelate titration. The existence of both calcium and magnesium soaps with a ratio of about $3.64: 1$ were determined. Thin layer chromatogram of the EtOAc layer showed nearly identical patterns to that of bark acids. Only the small amounts of metallic soaps remained in the mill deposit may be ascribed to the minute amounts of organic acids in bark resin and possibly the low concentraction of ionic inorganics. Deuok and Allen (1980) stated that in kraft pulping, deposited pitch contained about $30 \%$ of metallic soaps, in which both fatty acids and resin acids were combined with calcium ions from process water to produce insoluble pitch. Soda cooking of pokasa barks requires lower temperature and shorter time. Only a small quantites of acids were released from the bark extractives into the aqueous media to enable the combination with metallic ions.

\section{Ash in Deposited Substances}

After extraction of deposited substances with acetone and chloroform in sequence,

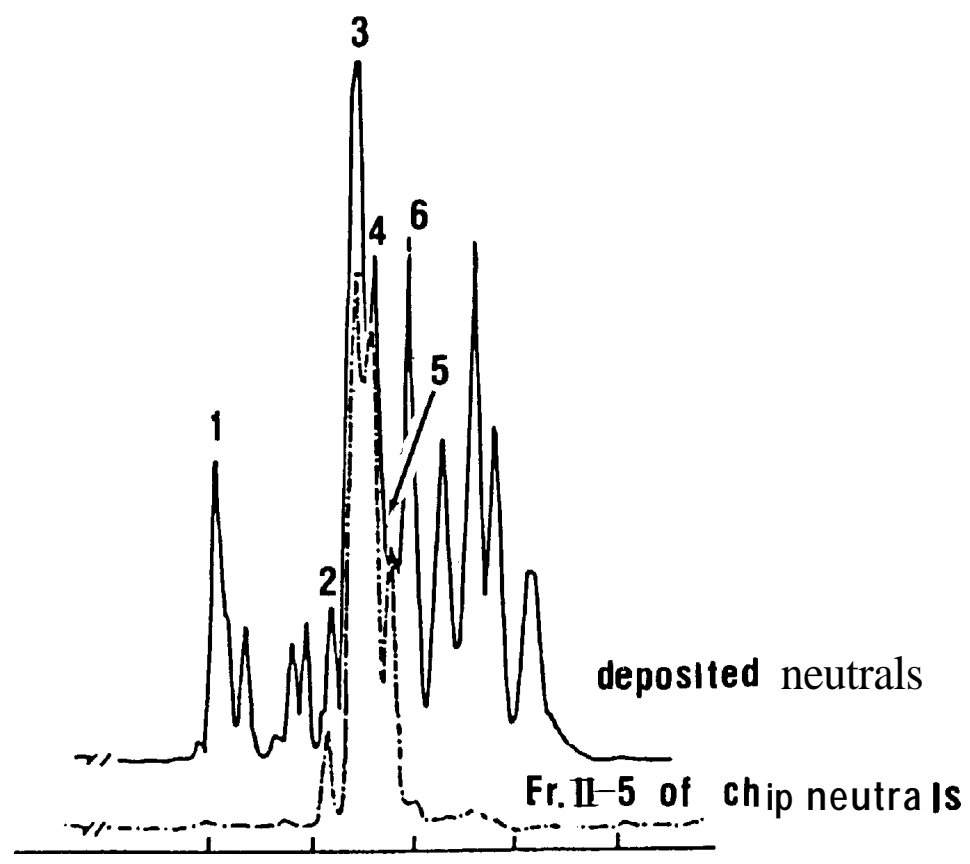

Fig. 3. Comparlson of fr. II-5 from bark neutrals and corresponding fraction of deposited neutrals.

Note Column : Develosil 60-3 $\phi 20$ x 250nm, Solvent ; llexane : ethyl ether - 20:1, flow rate $; 9.9 \mathrm{ml} / \mathrm{min}$, Det $; 210 \mathrm{~nm}, 1$ : lupenyl formate, 2 : a-amyrin, $3: \alpha^{-}$ amyrin, $4 ; \beta$-amyrin, 5 ; bauerenyl acetate, 6 : lupenyl acetate. 
Table 3. Composition of the deposited substances to the cooking equipment.

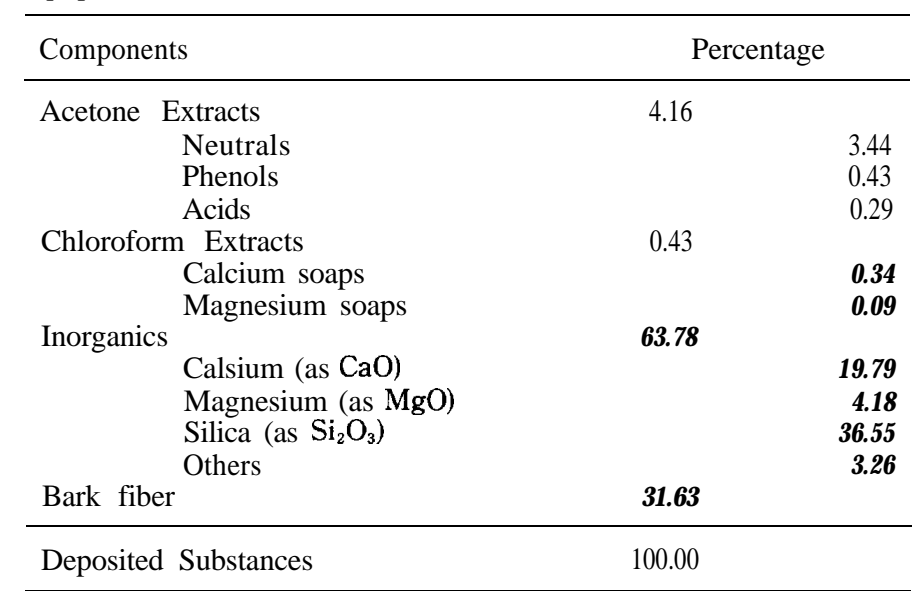

the residues were incinerated in an electric furnace to produce ash fraction. Determination of calcium and magnesium in the ash was made by the method of chelate titration. As shown in Table 3, more than half of the total inorganics was silica, followed by calcuim and magnesium. Relatively high content of silica may be accumulated over long periods of mill operation. Determination of carbonates in the deposited inorganics showed that about $80 \%$ of calcium and magnesium were in the form of carbonates. The carbonates may arise mainly from pokasa bark and partly produced during pulping.

\section{Mass Balance of Inorganics in Pulping and Bleaching}

Ash contents of bark and pulp at different stages were shown in Table 4. About half of the inorganics remained in UP. Part of the rest were dissolved in the aqueous cooking liquor. Some inorganic particles may be released into suspension when the bark is broken into fibers. Among them, only $20 \%$ of calcium and two-thirds of magnesium were lost during pulping. In kraft pulping, a significant dissolution of calcium and magnesium from wood during cooking was reported. The amount of magnesium in cooking liquor increased as cooking proceeded. However, the amount of dissolved calcium was dependent on the concentration of carbonate ions and also on the temperature of the liquor (Hertler and Libert, 1972 a, 1972b).

This seems to be the case for pokasa cooking as well. Both drastic decrease in the amount of magnesium and comparatively less decrease in calcium were found after cooking as mentioned previously. As shown in Table 3, however, the ratios of metallic carbonate in UP compared to that in bark was found to be $62.3 \%$ and $53.6 \%$, respectively. Similarly to the change in magnesium, silica decrease greatly suggesting its relative minor contribution to the formation of ink-repellent specks as mentioned previously (Su et al., 1986, 1992). In the cooking stage, at least a part of the great increase in the ratio of metallic carbonate may be due to the formation of new carbonate during the cooking. 
In hypochlorite bleaching, just like alkaline cooking, about 55\% of inorganics in UP were removed. This may be one of the major reasons for speck reduction at the stage. As a result, however, the ratio of calcium to total ash in BP grew higher than that in UP. This might be caused not only by the chemical conversions but also by repeated washing. The ratio of metallic carbonate to total calcium and magnesium in BP, i.e. $60.6 \%$, showed slight decrease as compared to the $62.4 \%$ in UP. All the above facts, might contribute to speck reduction during bleaching.

\section{Contribution of Calcium Salts to Speck Formation}

Based on the results described previously (Su et al., 1984, 1986) the importance of calcium ions in the formation of ink-repellent specks was established. However, at least some of calcium present in the bark tissue was found to be calcium carbonate as discussed in the previous section. Most of calcium in the plant tissue exists in the form of calcium oxalate or carbonate, and only a small part is in ionic form (Satoh and Tsutsumi, 1985). In alkaline cooking of pokasa, few new metallic ions were formed due to the inhibitory effect of high $\mathrm{pH}$ in the system. On the contrary, metallic ions were often reduced during cooking, resulting in higher metallic carbonate content as shown in Table 4. This also agrees with the facts in kraft pulping. As mentioned in the precious section, calcium ions, carbonate, and oxalate $\left(\mathrm{CaC}_{2} \mathrm{O}_{4}\right)$ were believed to have some effects on speck formation.

Speck formation tests were made by using acid-washed UP containing $0.22 \%$ of calcium (as $\mathrm{CaO}$ ) as a control. Methanol extractives of the bark were added to the pulp, then $\mathrm{CaCl}_{2}, \mathrm{CaCO}_{3}, \mathrm{CaC}_{2} \mathrm{O}_{4}$, were added separtely and treated as described in a previous paper ( $\mathrm{Su}$ et $\mathrm{al}, 1986)$. As shown in figure 4, either ionic or solid calcium produced high levels of speck areas. However, ionic calcium caused specks with higher retainability in pulps than those of the solid calcium. Calcium carbonate can be formed during cooking, and reabsorbed onto the pulp fiber. Dissolved calcium $\left(\mathrm{Ca}^{++}\right)$, on the other hand, can combine with fatty acids and resin acids to form insoluble soaps which end up in deposits (Abram and Nelson, 1977). In contrast, the hydrophobic surface of $\mathrm{CaCO}_{3}$ particles act as scavengers in the system for all types of oily and fatty materials, as well as fillers which binds resionous materials together including souble soaps to the fibers (Zimmels et al., 1975).

\section{Deposition Mechanisum Due to Interaction of Calcium and Resinous Materials}

A number of mechanisms for pitch deposition in papermaking have been suggested by many authors (Back, 1960), (Vincent, 1964), (Swanson, 1956). These mechanisms can be classified as by physical or/and chemical nature of resin and also by physicochemical characters of the resin (Allen, 1980), (Tachibana and Sumimoto, 1980), (Ohtani and Sumimoto, 1981). But deposition mechanism due to interactions of resinous materials with calcium compounds was not clearly shown. Based on the previous discussions and on characteristic properties of calcium compounds, especially $\mathrm{CaCO}_{3}$ (Greene and Reader, 1974) mechanism of this kind is considered to be similar to that of resin sizing (Usuii, 1983), the dying mechanism of complex pigments (Ueno, 1981) and complex formation between glucopyranside and magnesium ions (Nunn and Linde, 1980).

A hypothetical mechanism is represented as follows. 
Table 4. Changes in the amounts of inorganics at the different stages.

\begin{tabular}{|c|c|c|c|c|c|}
\hline Compenents & & Bark Neutrals* & UP Neutrals* & BP Neutrals* & $\begin{array}{c}\text { Deposited } \\
\text { Neutrals }\end{array}$ \\
\hline \multirow[t]{4}{*}{ Total } & Ash & $4.70^{\mathrm{a})}(100)^{\mathrm{d})}$ & $3.85^{\mathrm{b}}(47.4)^{\mathrm{d})}$ & $1.83^{\mathrm{c}}(21.3)^{\mathrm{d})}$ & $63.78 " '$ \\
\hline & $\mathrm{CaO}$ & $1.65^{\mathrm{a})}(35.5)^{\mathrm{d})}$ & $2.29^{\mathrm{b}}(28.2)^{\mathrm{d})}$ & $1.19^{\mathrm{c}}(13.8)^{\mathrm{d})}$ & $19.79 "$ \\
\hline & $\mathrm{MgO}$ & $1.53^{\mathrm{a})}(32.6)^{\mathrm{d})}$ & $0.73^{\mathrm{b})}(8.9)^{\mathrm{d})}$ & $0.38^{\mathrm{c})}(4.5)^{\mathrm{d})}$ & $4.18^{\mathrm{e})}$ \\
\hline & $\mathrm{Sl}_{2} \mathrm{O}_{3}$ & $1.04^{\mathrm{a})}(22.1)^{\mathrm{d})}$ & $\left.0.72^{\mathrm{b}}\right)(8.9)^{\mathrm{d})}$ & $0.18^{\mathrm{c}}(2.3)^{\mathrm{d})}$ & $36.55 " '$ \\
\hline Others & & $0.48^{\mathrm{a}}\left(12.2^{\mathrm{d})}\right.$ & $0.11^{\mathrm{b})}(1.3)^{\mathrm{d})}$ & $0.06^{c)}(0.6)^{d)}$ & $3.26 " ”$ \\
\hline $\mathrm{CaCO}_{3}$ & $\mathrm{CaO}$ & $53.57 ”$ & $62.43 "$ & $60.58^{\mathrm{F})}$ & 78.42 \\
\hline $\mathrm{MgCO}_{3}$ & $\mathrm{MgO}$ & & & & \\
\hline
\end{tabular}

${ }^{\text {a) }}$ Percent based on bark chip. b)Percent based on unbleached pulp.

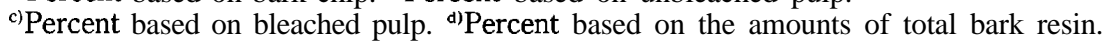

e)Percent based on the deposited substances.

${ }^{\text {f) }}$ Ratio of $\mathrm{CaCO}_{3}{ }^{+} \mathrm{MgCO}_{3}$ to $\mathrm{CaO}+\mathrm{MgO}$.

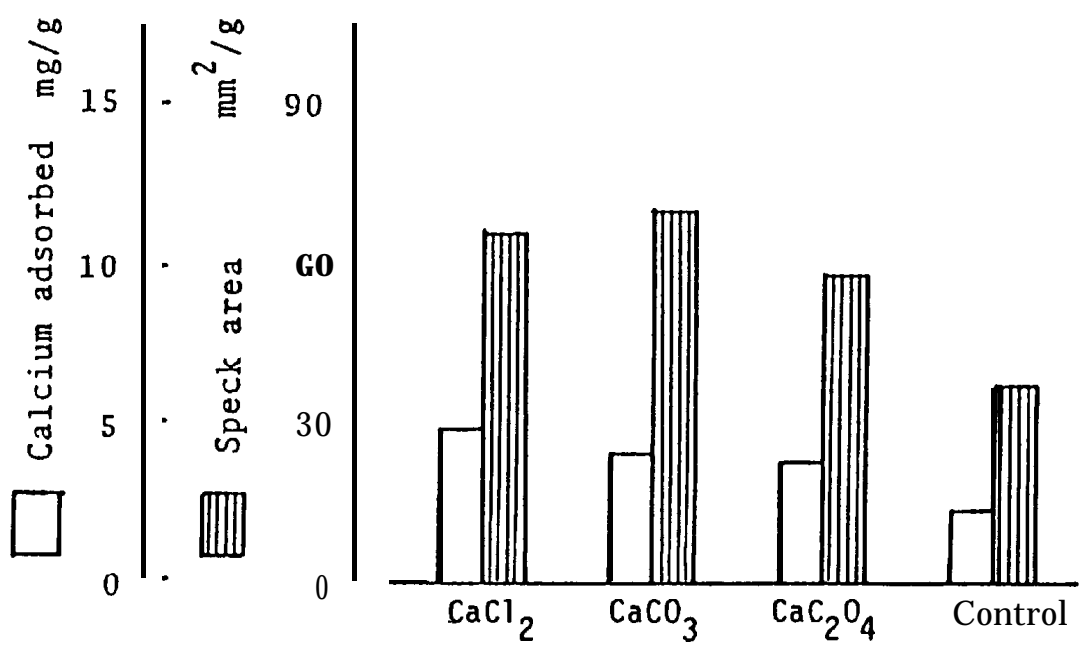

Fig. 4. Speck fornation and the amount of adsorbed calcium of various types in the re-addition test.

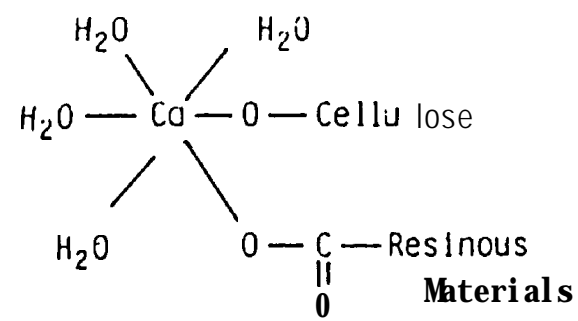

Fi g. 5. Possible structure of the complex. 
1. Acidic components react with $\mathrm{Ca}++$ or $\mathrm{Ca}^{++} \mathrm{Co}_{3}{ }^{=}$to form a salt or a complex with $(+)$ charge, which are adsorbed onto pulp with (-) charge on its surface.

2. In pulpingm, $\mathrm{Ca}^{++}$ions are generated and adsorbed onto surrounding resinous materials to form colloids with $(+)$ charge which are adsorb onto pulp with $(-)$ charge. 3. Calcium carbonate in aqueous medium may be coordinated by six molecules of $\mathbf{H}_{2}$ 0 to form $\mathrm{Ca}\left(\mathrm{H}_{2} \mathrm{O}\right)^{++6}$, which owing to the coordinates properties of ligand $\mathrm{OH}-$ anion, tends to subsituted $\mathrm{H}_{2} \mathrm{O}$. As shown in the Figure 5, resinous materials may be bonded with the ion and also with hydroxyl group in cellulosic fibers.

4. As mentioned in a previous papers ( $\mathrm{Su}$ et al., 1984) drying of a paper sheet at room temperature produced almost no ink-repellent speck but at the elevated temperature. Low melting points resinous mixtures might migrate toward calcium even from neighboring fiber to form ink-repellent specks.

\section{CONCLUSIONS}

1. Extractives of pokasa (Brossonetia papyrifera) bark, UP,BP, and deposited substances from a paper mill were compared from the point of mass balance. Through the sequence of the pulping and bleaching, little differences among the organic fractions were noted. Better recovery yields of Fr.II in UP as well as BP neutrals inferred the lower solubility in aqueous phase and the higher depositability of this fraction to pulp. However, high yield of Fr.II among deposited neutrals also confirmed the high depositability. Fr.II containing triterpenoid and steriod alcohol esters which were stable in the cooking and bleaching media and remained in pulps or adhered to the cooking equipment.

1. Resi nous material s $+\mathrm{Ca}^{++}$or $\mathrm{CaCO}_{3}$ $\longrightarrow$ Calcium salts or calci umorganics compl exes with $\oplus$ charge

$\longrightarrow$ Adsorbed onto the pul p fibers which have $\theta$ charge on the surface.

2. Colloi dal resi $n$ particles $+\mathrm{Ca}^{++}$or $\mathrm{CaCO}_{3}$ $\longrightarrow$ Cationic colloidal particles

$\longrightarrow$ Adsorbed onto the pulp fibers which have $\theta$ charge on the surface.

3. $\mathrm{CaCO}_{3}(\mathrm{~s}) \rightleftharpoons \mathrm{Ca}\left(\mathrm{H}_{2} \mathrm{O}\right)_{6(\mathrm{aq})}^{++}+\mathrm{CO}_{3}^{=}(\mathrm{aq})$

$\mathrm{Ca}\left(\mathrm{H}_{2} \mathrm{O}\right)_{6}^{++}(\mathrm{aq})+\mathrm{OH}^{-} \rightleftharpoons\left[\mathrm{Ca}(\mathrm{OH})\left(\mathrm{H}_{2} \mathrm{O}\right)_{5}\right]_{(\mathrm{aq})}^{+}+\mathrm{H}_{2} \mathrm{O}$

$\left[\mathrm{Ca}(\mathrm{OH}) \quad\left(\mathrm{H}_{2} \mathrm{O}\right)_{5}\right]^{+}+\mathrm{OH}^{-}=\left[\mathrm{Ca}(\mathrm{OH})_{2}\left(\mathrm{H}_{2} \mathrm{O}\right)_{5}\right]_{(\mathrm{aq})}^{\mathrm{O}}+\mathrm{H}_{2} \mathrm{O}$

Fig. 6. Hypothetical mechanism of Ink-repellent specks. 
2. High carbonate contents in the inorganics of pokasa pulp showed that calcium carbonate was formed during pulping and readsorbed onto pulp fibers.

3. The calcium salts, $\mathrm{CaCl} 2, \mathrm{CaCo} 3$, and $\mathrm{CaC} 204$ have about the same level of effect on speck formation but differ in their retentious onto the pulp fibers.

4. A hypothetical mechanism for the interaction among resinous material, calcium, and fibers was proposed on the basis of rosin sizing and dying mechanisms of complex pigment (Fig. 6, Fig. 7).

\section{REFERENCES}

Abe, Z. 1987 The behavior of wood resin during kraft pulping and pitch problems. part I. Chemical
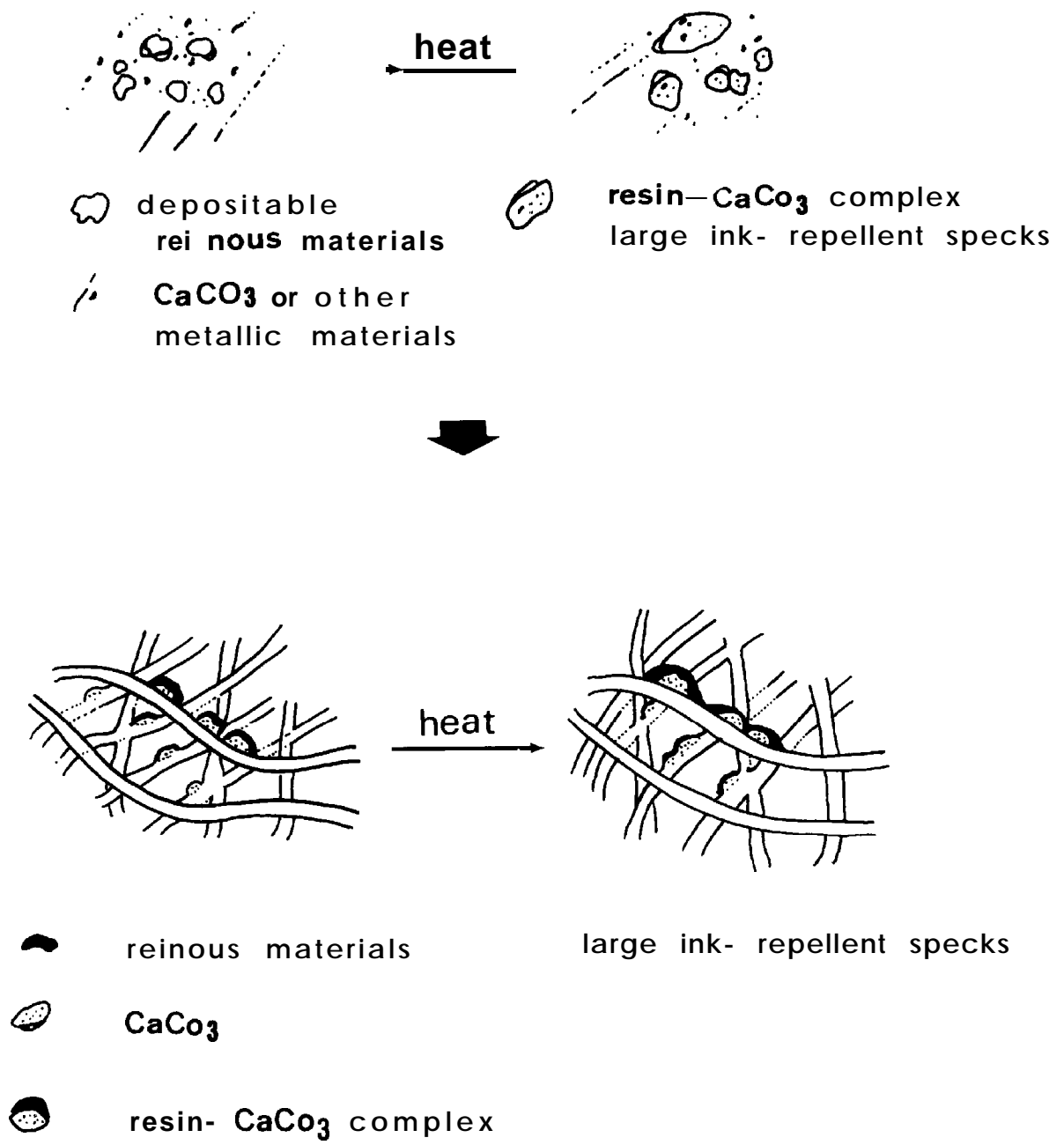

large ink- repellent specks

Fig. 7. Mechanism of Ink-repellent speck formation. 
change in wood resin and resin balance. Japan Tappi 41: 417-423.

Abram, E. and Jr. Nelson 1977 A system approach to control of kraft mill deposits. Tappi 60(10): 109-112.

Allen L.H. 1980 Mechanism and control of pitch deposition in News print mills. ibid, 63(2): 81-87.

Back, E. 1960 The mechanism of pulp resin accumulation at solid surfaces, Svensk Papperstidin 63: 556-565.

Back, E. 1960 Resin in confier pulpwood and fundermentals of pitch control in pulp and paper manufacture. Svensk Papperstidin 63: 793-802.

Deuok, N. and L. H. Allen 1980 The distribution of calcium in kraft mill brownstock systems. ibid, 83: 425-429.

Greeme, B.W. and A.S. Reader 1974 Electro kinetic and rheological properties calcium carbonate dispersions used paper coatings. Tappi 57: 101-106.

Hertler, N. and J. Libert 1972 Structure and composition of scale in continuous kraft digesters, Svensk Papperstidin 75: 65-70.

Hertler, N. and J. Libert 1972 The inorganic content of wood. ibid, 75: 305-309.

Kayama, T. 1967 Kraft pulping and papermaking characteristics of some Cambodian woods Japan Tappi 21: 135-140.

Kayama, T. 1968 Tropical wood pulping. Japan Tappi 22: 175-189.

Nunn, J. R. and M. J. Linde 1980 The protective action of Magnesium in oxygen bleeding of pulp. Part I. Proceeding of first International symposium on Delignification with oxygen and ozone and peroxide. Uni Publisher, Tokyo, pp.79-88.

Ohtani, T. and M. Sumimoto 1981 Studies on pitch troubles caused by pulping and bleaching of tropical wood (IX). Colored specks formed on a sulfate pulps from rengas wood 3. Mokuzai Gakkaishi 27: 302-310.

Satoh, D. and Y. Tsutsumi 1985 "Zyumoku-Keitai to kinou” Muneitoh, Tokyo, pp. 167-185.

Shimada, K. 1969 Studies on the pitch trouble of tropical wood pulp I. Extractives of Bangkirai and keruing remain in sulfate pulp and their influence in bleaching. Mokuzai Gakkaishi 15: 126 130.

Shimada, K. 1970 Studies on the pitch trouble of tropical wood pulp II. Behavior of hydroxydammarenone II during bleaching and influence of its reaction products on pulp. Mokuzai Gakkaishi 16: 388-393.

Su, Y-C., H. Tanaka, and M. Sumimoto 1984 Pitch problems in making Japanese papers. Part I. Formation mechanism and removal methods. Mokuzai Gakkaishi 30: 490-500.

Su, Y-C., H. Tanaka, and M. Sumimoto 1986 Pitch problems in making Japanese papers. Part II. Contribution of inorganics to speck formation and separation and identification of the neutral components in $\mathrm{MeOH}$ extractives. ibid, 32: 190-202.

Su, Y-C., H. Tanaka, and M. Sumimoto 1992 Pitch problems in making Japanese papers. Part III. Separation and identification of acidic components and their contribution to speck formation. $J$. Fac.Agr., Kyushu univ. : in preparation.

Swanson, J. W. and R. H. Cordingly 1956 Surface chemical studies on pitch I. A new approach to the pitch problems in papermaking. Tappi 39(10): 684-690.

Swanson, J. W. and R. H. Cordingly 1959 Surface chemical studies on pitch II. The mechanisms of the loss of absorbancy and development of self sizing in papera made from wood pulps. ibid, 42: 812-820.

Tachibana, S. and M. Sumimoto 1980 Studies on pitch troubles caused by pulping and bleaching (VI). Phenolic wood extractives responsible for yellow specks. Holzforschung 34(4): 131-137.

Ueno, M. 1981 "Nyumon kereto kagaku” Nankodoh, Tokyo, pp. 262-265.

Usuii, M. 1983 Overview and prospect of paper chemicals. Pulp and paper engineering 26(4): 39-47. Vincent, D. L. 1957 Studies on pitch deposition. Pulp and Paper Mag. Can., 18: 150-165.

Zimmels, Y., I. J. Lin, and J. P. Friend. 1975 The relation between stepwise bulk association and interfacial phenomena for some aqueous surfactant solutions. Colloid Polymer Sci. 253: 404-421. 